\title{
Lo neofantástico y lo abyecto en Falsa fiebre y Temporada de huracanes de Fernanda Melchor ${ }^{1}$
}

\author{
The Neo-Fantastic and The Abject in Falsa liebre (False Hare) \\ and Temporada de buracanes (Hurricane Season) \\ by Fernanda Melchor
}

\author{
José Manuel SuÁrez Noriega \\ ORCID: 0000-0001-8540-1038 \\ Tecnológico de Monterrey, México. \\ jmsuarez@tec.mx
}

Resumen:

El presente ensayo tiene como objetivo el abordar lo abyecto como vehículo estilístico y de contenido necesario para superar la repulsión y el rechazo hacia la abyección y entrar al terreno del pensamiento crítico sobre la naturaleza humana. Para ello, se presentarán algunas aproximaciones teóricas a dos novelas mexicanas contemporáneas: Falsa liebre (2013) y Temporada de buracanes (2017) de la escritora veracruzana Fernanda Melchor. Lo que estas novelas tienen en común es la caracterización derrotista y fragmentaria de sus personajes, el carácter neofantástico de sus historias a través de la aparición de lo insólito y lo sobrenatural, y la inclusión de la abyección como contenido y

${ }^{1}$ Una versión preliminar de este texto fue presentada en noviembre de 2019 durante el XXVII Coloquio Internacional de Literatura Mexicana e Hispanoamericana de la Universidad de Sonora, México. En aquel momento, el título de este trabajo era "La armonía de lo abyecto: apuntes para un análisis literario de Falsa liebre y Temporada de huracanes de Fernanda Melchor". 
forma. Finalmente, la combinación de los elementos anteriores dota de un sentido lírico a lo que, tradicionalmente, podría considerarse como grotesco y transgresor. Este sentido lírico y estético va más allá de la estilística: es el puente que conduce a la reflexión moral sobre la compleja, inacabada y ambivalente condición humana.

\section{Palabras clave:}

abyección, neofantástico, literatura mexicana contemporánea, condición humana.

Abstract:

The purpose of this essay is to address some aspects of the abject as a literary vehicle to overcome repulsion and rejection towards the abject. Also, this form of aesthetics may bring about critical thinking about human nature. To this end, some theoretical approaches will be used in approaching two Mexican novels, Falsa liebre (False Hare) and Temporada de huracanes (Hurricane Season), by contemporary Mexican writer Fernanda Melchor. What these novels have in common is the defeatist and fragmented characterization of their characters; the neo-fantastic nature of their stories through the recurrent references to the supernatural, and the inclusion of abjection as content and form. Finally, the combination of these elements gives a lyrical sense to what, traditionally, could be considered as grotesque and transgressive. This lyrical sense goes beyond stylistics: it is the bridge that leads to moral reflection on the complex, unfinished, and ambivalent human condition.

Key words:

abjection, neo-fantastic, contemporary Mexican literature, human condition.

DOI: https://doi.org/10.36798/critlit.vi21.331

Recibido: 05 de febrero de 2020

Aceptado: 31 de mayo de 2020 
Fernanda Melchor, escritora mexicana nacida en Veracruz en 1982, ha recibido importantes galardones y reconocimientos a pesar de contar con solo dos novelas y un libro de relatos. En 2019, su segunda novela, Temporada de huracanes, fue galardonada con el premio Anna Seghers (Alemania) y el Premio Internacional de Literatura de la Casa de las Culturas del Mundo (Alemania). En 2020 fue nombrada finalista del premio Booker Internacional del Reino Unido. La crítica nacional e internacional han puesto sobre la mesa el trabajo ${ }^{2}$ de Melchor como uno de los más promisorios de Latinoamérica.

En su narrativa aparecen mundos en los que la ficción es auténticamente corrosiva; el uso del lenguaje es inteligente, mordaz y sensible, y la armonía entre forma y contenido se da a través de una poética transgresora. Sus personajes parecen estar subyugados al imperativo del destino que recuerda a la irrevocabilidad del sino griego y sus acciones llegan a traspasar los límites de lo socialmente aceptable. Este trabajo se centrará en sus dos novelas: Falsa liebre (Almadía 2013) y Temporada de huracanes (Random House 2017) a partir de tres rasgos que tienen en común: 1) personajes caracterizados desde su marginación social o conductual dominados por la fragmentación de sus relaciones interpersonales y el derrotismo en su devenir; 2) la recurrencia a lo «neofantástico», término acuñado por

${ }^{2}$ Especialmente, Temporada de huracanes le ha dado mayor visibilidad internacional a la narrativa de Melchor. Como muestra de ello, a continuación se presenta un fragmento de la revisión que Julian Lucas hace de la novela para The New York Times el 31 de marzo de 2020: "Melchor has an exceptional gift for ventriloquism, as does her translator, Sophie Hughes, who skillfully meets the challenge posed by a novel so rich in idiosyncratic voices. Rage, anxiety and a contempt laced with carnival humor are the keynotes. . . 'Hurricane Season' belongs to the Gothic-grotesque tradition of the transnational American South. The novel's tortured self-deceptions and sprung-trap revelations evoke the stories of Flannery O'Connor, or, more recently, the neuroses of Marlon James's Kingston gunmen in 'A Brief History of Seven Killings' In an interview about that novel, James spoke about the need to 'risk pornography' in the portrayal of violence — and Melchor certainly does. At times, she enters so deeply into the psyche of sexual violence that she skirts the voyeurism risked by any representation of cruelty". 
Jaime Alazraki, por medio de la aparición constante de lo insólito y lo sobrenatural; y 3) la estética de lo abyecto en cuanto a la ruptura de las fronteras de lo aceptado y lo establecido por el orden social. La abyección aquí se analizará en términos de la teoría de Judith Butler como el rechazo a la homosexualidad; y la abyección desarrollada por Julia Kristeva, como la representación explícita de la muerte, la corporalidad de lo repulsivo y las conductas que sobrepasan los límites de lo moralmente deseable. Por lo anterior, el objetivo de este ensayo es evidenciar que la abyección, entendida como una extralimitación de las fronteras sexualmente heteronormadas, físicas, morales y conductuales es fundamental en ambas novelas para poner de manifiesto una poética de lo amoral, lo fragmentario, lo repulsivo, lo extraño y lo incómodo. El valor de la narrativa de Melchor radica en la libertad que ofrece a los lectores para que estos sean quienes adopten una postura frente a las acciones y condiciones abyectas haciendo evidente, en todo momento, la deliberada ficción literaria que, lejos de imponer una visión maniqueísta de la realidad, confronta al lector con sus prejuicios y límites morales.

Falsa liebre es narrada por una voz omnisciente que emplea digresiones y analepsis. Los tiempos no son cronológicos y esto conduce a una sensación de suspenso y tensión constantes. Se divide en dos partes y cada una en cuatro capítulos cuyas focalizaciones van variando: el primero se centra en Andrik, un chico de catorce años; el segundo en Pachi, de diecinueve años; el tercero en Zahir, supuesto hermano de Andrik; y el cuarto en Vinicio, amigo de Pachi. La novela se construye alrededor de un contrapunto que comienza a cobrar forma en la segunda parte y en el que las cuatro historias tienen relevancia. Sin embargo, es la historia de la prostitución y constante huida de Andrik a la que se dota de mayor atención a lo largo de la novela. En los capítulos se entremezclan varias líneas narrativas, pensamientos, recuerdos, añoranzas por medio de un lenguaje coloquial, diálogos y abundante analepsis. Se presenta la ordinariez de vidas clasemedieras que sobreviven entre la rutina y la promesa de la distracción en ambientes tanto naturales como artificiales alrededor del puerto de Veracruz. En los personajes no se vislumbran aspiraciones ni intelectuales ni espirituales. Solamente 
materiales y, si acaso, afectivas, aunque estas rayan en la obsesión, la codependencia y la violencia. Los personajes masculinos son presa del miedo, de la preocupación por su autoimagen y, principalmente, muestran una continua contención emotiva. Los personajes femeninos son presa de un frenesí, una desarticulación emocional productos de la ira, el odio, el rencor y la pérdida de control.

Temporada de huracanes emplea el estilo indirecto libre con una presencia fuerte de la conciencia de los personajes, una marcada polifonía y actos de pensamiento entremezclados con actos de habla. Hay un narrador que varía de la tercera persona singular a la tercera persona plural y que, por momentos aparece extradiegéticamente y, por otros, intradiegéticamente. Es una novela de ocho episodios escritos de manera corrida sin espacios entre párrafos. Los tiempos narrativos se yuxtaponen lo mismo que las historias que se van enlazando en una especie de concatenación de ideas y contrapuntos. La acción comienza el primer lunes de mayo cuando un grupo de niños encuentra el cadáver putrefacto de La Bruja. A partir de este incidente, los siguientes episodios emplean estrategias narrativas tales como el testimonio, el rumor, la analepsis, la prolepsis y las digresiones para dar los antecedentes de La Bruja y la investigación sobre su asesinato en el que Luismi y Brando están involucrados. Aparece el testimonio de Yesenia, prima de Luismi, quien constata su odio hacia este y el rencor hacia su abuela muerta. Posteriormente, la focalización se centra en Munra, padrastro de Luismi y en la historia de Norma, la menor de edad involucrada con Luismi y cuya aparición en la vida de este, marcará profundamente el rumbo que toma la trama de la novela. Finalmente, los dos últimos episodios hacen uso de una narración omnisciente. El VII presenta la voz popular del rumor, centrándose en lo que pasó después del asesinato de La Bruja: el encuentro macabro del cadáver de su madre vuelta huesos y polvo en la cama de la habitación que había permanecido tapiada por años; el destino siniestro del comandante a cargo de la investigación y la plegaria de las mujeres del pueblo, quienes claman por respeto al dolor de las que habitaron la casa legendaria: La Bruja y su madre. El último episodio también emplea una voz omnisciente: se habla del Abuelo quien, 
en su función como sepulturero en una fosa común, va contando uno a uno los cadáveres que van llegando, los retazos de personas, los mutilados, los cuerpos descuartizados, abandonados a su suerte y a la podredumbre, cuerpos del crimen, cuerpos del olvido. En este episodio ya no se hace referencia a los personajes de la novela. En él se vislumbra que la temporada de lluvias está por llegar y con ella termina la canícula a la que, en episodios anteriores, los personajes se refieren como causante de la ola de violencia en la región.

\section{Relaciones humanas fragmentadas}

Fernanda Melchor delinea, en sus dos novelas, personajes - tanto masculinos como femeninos- que participan de igual manera en la opresión, la crueldad, la discriminación, el abuso del poder y el fracaso existencial. Hay fragmentación de identidad y fragmentación relacional o, todo lo contrario, relaciones compulsivas y codependientes. Ambas novelas rompen con ideas tradicionalmente arraigadas y con mitos sobre lo femenino y lo masculino. Un ejemplo de ello es el tratamiento que dan a la maternidad. En Temporada de buracanes se afirma que:

eso de tener hijos está de la verga... a la mera hora es una la que tiene que partirse la madre para sacárselos de adentro, y partirse la madre para cuidarlos, y partirse la madre para mantenerlos, mientras el cabrón de tu marido se va de pedo y se aparece cuando se le hincha la gana. (145)

Mientras que en Falsa liebre las figuras estereotípicas de las mujeres protectoras son desmanteladas para presentar madres alcohólicas, violentas, crueles, desapegadas de sus hijos; madres que se ensañan con ellos y les generan culpas y sentimientos ambivalentes:

[Andrik] se inclinó para besarle la base de la nuca. Ella lanzó un chillido de furia y dejó caer sus puños cerrados sobre el chico. Buscaba su cara, sus mejillas, su vientre, las partes menos duras de ese cuerpo que era todo ángulos, carne de niño 
sobre huesos que comenzaban a engrosarse. Andrik sólo atinó a cubrirse el rostro, protegerse los ojos de aquellas uñas que dejaban surcos escarlata a lo largo de sus brazos. Todo terminaría pronto, si permanecía quieto, si no ofrecía resistencia. (132)

El resultado es un amplio catálogo de relaciones interpersonales destructivas como la de Yesenia y su abuela en Temporada de huracanes:

Y supo también, mientras se hundía en los ojos cada vez más rabiosos de la vieja, que su abuela la odiaba con toda su alma y que en aquel mismo momento la estaba maldiciendo, y Yesenia, con un hilito de voz, quiso pedirle perdón y explicarle que todo había sido por su propio bien pero fue demasiado tarde: una vez más, la abuela le había dado a Yesenia en donde más le dolía, y por eso se murió en aquel momento, temblando de odio entre los brazos de su nieta la más grande. (59)

Esta ambivalencia limítrofe aparece también en Falsa liebre en Zahir, cuya misión es rescatar a Andrik, huir con él y hacer una vida juntos:

[Zahir] le rodeó el cuello con un candado hasta que se quedó quieto y luego rompió a llorar de impotencia. No quería lastimar a su hermano pero no podía dejarlo ahí: la marea subía. Le llenó el rostro de besos, mientras lo acunaba, sentados en la arena. ... Había estado tan cerca de perderlo, en el bosque. No volvería a pasar. No lo soltaría nunca. Aunque [Andrik] pareciera no reconocerlo, aunque luchara por librarse de sus brazos, aunque no dejara de chillar como una bestia acorralada. (190)

Se trata de personajes que, de acuerdo con el teórico Gérard Imbert, son border y a los que define como:

sujetos en ruptura con el sistema, a la deriva ... se sitúan en los bordes y pueden caer en conductas al margen de la norma y en conductas de riesgo. Se caracterizan por tener relacio- 
nes interpersonales caóticas y un comportamiento fácilmente descontrolado. Viven en estados de ánimo inestables, en un continuo vértigo emocional [pues] han perdido la noción de los límites. (266)

Aunado al carácter border y a las ambivalencias emocionales al interior de todos los personajes de Fernanda Melchor, la escritora narra mundos de adolescentes y adultos que viven entre las drogas y el alcohol; en los que el sexo es un acto violento y la rabia contenida se desborda en fantasías de destrucción y crimen. Personajes que buscan huir de su propia vida y que, sin embargo, permanecen estáticos y encolerizados en ella. No existe un atisbo de heroicidad en ellos. Los personajes aquí se duelen ante su dolor; se revuelcan en él y lo maldicen. Pero lo habitan, lo abrazan y, por momentos, embrutecidos por el alcohol, la piedra, el "chemo" o la mota, logran ahuyentarlo; mas el miedo siempre aparece y les orilla a actuar en los límites de lo moral y lo socialmente aceptado.

Una constante es que los personajes viven en la añoranza de un momento en el que fueron plenos, quizás un momento en la infancia o en la temprana adolescencia, y al que se aferran o del que se sostienen mientras lamentan su presente lastimero. En estas novelas no hay lugar para imaginar un mundo mejor o un futuro promisorio; la fantasía y los sueños se estrellan constante y violentamente contra su apabullante realidad. Un ejemplo de esto se encuentra en Falsa liebre. El día de su cumpleaños trece, Andrik parte a la feria de Carrizales con Esteban, hombre mucho mayor que él y por quien se ilusiona románticamente. En la descripción de la feria hay un juego sensorial contrastante de colores, texturas y olores que van del ensueño a la decepción para el chico. Comienza con Andrik comiendo un algodón de azúcar: "Las hebras de azúcar se deshicieron en contacto con la humedad de su boca ... Lamió una parte del algodón hasta derretirla en grumos de miel azul oscura; la fue chupando mientras caminaba: sabía dulce pero era algo decepcionante" (138). Posteriormente, se describe una pelea de gallos:

El aire ahí dentro olía a plumas ensangrentadas, gallinaza, al sudor agrio de los campesinos ya ebrios. ... Andrik se de- 
cepcionó de la fealdad de los gallos; les habían cortado las crestas, las golillas, las plumas del lomo y de la cola. Con las piernas y los pescuezos desnudos parecían zopilotes de rastro. (140)

Sin embargo, como interludio, aparece un breve instante de ensueño para el niño cuando Esteban le explica al oído el significado de la palabra jumper: "Su aliento olía a fruta dulce. Sus caras estaban tan cerca que hubiera bastado que Andrik frunciera los labios para plantarle un beso en la mejilla (140); pero, el ensueño se rompe de inmediato y la descripción del final de la pelea se torna violenta y cruda:

Andrik volvió la vista al ruedo pero no alcanzó a ver el final de la pelea, solo el chisguete de sangre que manaba del cuello reventado del gallo blanco y que manchaba sus plumas y la arena. ... El amarrador se acercó al cuerpo aún trémulo del gallo giro, y tomándolo del pescuezo, lo arrojó fuera del ruedo, hacia el montículo de patas tiesas y picos quebrados que mosqueaba en un rincón junto a las gradas. (140)

No hay espacio para las ensoñaciones ni para la realización de los planes ilusorios de los personajes. El derrotismo y el desasosiego marcan el sino de aquellos quienes intentan escapar de él.

Hacia el final de la novela, y tras fracasar en su intento por huir con Andrik, Zahir se encuentra vacío deambulando de regreso a su casa. Para enfatizar las emociones contradictorias y la fragmentación del personaje, la voz narrativa dice:

Ya no sentía el cuerpo, ni el suelo bajo sus pies, ni el calor húmedo que lo rodeaba. No sentía nada. Cada segundo era una eternidad dilatada; cada paso, idéntico al anterior y al siguiente. Apenas se dio cuenta de que trepaba el puente, que regresaba a la ciudad. . . Cruzó las calles ardientes sin mirar el tráfico, sin que le importara que los autos y los autobuses tuvieran que volantear para esquivarlo. Las aceras estaban llenas de gente pero Zahir no miraba a nadie. . . . Ni siquiera 
percibía las voces a su alrededor, ni los pregones de los vendedores ni la risa de los vagos al burlarse de él, creyéndolo drogado. (197-98)

Se trata de un andar a la deriva fruto de una obsesión enfermiza por llenar el vacío con el supuesto hermano al que, desde pequeño, sometió a su poder y voluntad erótico-sexual. El fracaso es ineludible y este se corporaliza con el andar pesado, la obnubilación de la mente de Zahir y el trazado de un recorrido que lo llevará a su encuentro final con el origen de toda su rabia contenida: la tía Idalia postrada en la cama, símbolo de la crueldad, la humillación y el odio hacía sí mismo.

La fragmentación relacional y la imposibilidad de realizar un devenir fructuoso también son constantes en Temporada de huracanes. Ninguno de los personajes logra realizar un proyecto de vida dirigido a la consecución de la felicidad y sus momentos de plenitud son interrumpidos por la avalancha inexorable de sucesos trágicos que comprometen sus voluntades. Una muestra de este constante ir y venir entre la ilusión y la desilusión se halla en Norma, la menor de edad embarazada quien, tras huir de su familia en busca del suicidio, termina encontrándose con Luismi, con quien intenta establecer una relación sentimental. Norma narra y recuerda en el hospital, amarrada a una cama, enjuiciada por las miradas de las enfermeras y su crueldad, que le recuerda a la crueldad de su madre. Norma rememora a Pepe, su padrastro: ella, una niña de doce años y él, un hombre de veintinueve, que comenzó a seducirla y ella a aceptarlo hasta que empezó a sentirse culpable por el placer experimentado precozmente. En esta relación incestuosa abunda la ambivalencia como signo: "y la besaba en la boca con un hambre salvaje que Norma encontraba a la vez deliciosa y repugnante" (133). Asimismo, la niña comprende que, en las caricias de su padrastro, su soledad es mitigada:

la forma en que sus dedos se deslizaban por la piel de Norma y delineaban los contornos de su cuerpo, caricias que nadie le había hecho nunca, ni siquiera su madre, ni siquiera en 
los buenos tiempos, cuando solo eran ellas dos y nadie más, y Norma no tenía que competir por ella, por su atención y cariño. (123)

Norma y el vacío, el desasosiego, la búsqueda de un cariño. Para Norma, cada nuevo hermano era una nueva carga que le tocaba llevar a cuestas. Con su padrastro establece una relación incestuosa que desde su origen conlleva el deseo paradójico de muerte y placer en la joven embargada por el odio a sí misma:

Norma quisiera escapar corriendo de aquel sitio, romper sus vendajes y huir como fuera del sanatorio, huir de su propio cuerpo adolorido, de esa masa de carne abotargada y henchida de sangre, de pavor y de orina que la mantenía anclada a la maldita cama... escapar de aquel lugar donde todos la miraban con odio, donde todos parecían saber lo que había hecho; estrangularse las manos, degollarse a sí misma en un grito elemental que, al igual que la orina, ya no pudo contener por más tiempo: mamá, mamita, gritó a coro con los recién nacidos. Quiero irme a casa, mamita, perdóname todo lo que te hice. (151)

El odio y la autocensura, la culpa y el arrepentimiento son claves constantes en Temporada de huracanes. Encuentran una de sus máximas expresiones en Brando, personaje fragmentado sumido en el rencor virulento hacia su propia existencia. Su sueño es huir de ese pueblo lleno de homosexuales a los que, según él, tendrían que quemar. Los recuerdos de infancia lo invaden: los zapatos de pobre que la madre le compraba en las tiendas donde también se surtía de muñecos de peluche que adornaban la sala, mismos que él rociaba de petróleo y quemaba mientras su madre pasaba todas las tardes en la iglesia: "Le daba coraje que su madre fuera tan pendeja, tan crédula; que por su culpa tuvieran que comer frijoles a diario, porque buena parte de lo que el padre de Brando les mandaba, que no era mucho, ella lo donaba al seminario" (160). Brando se siente perseguido por el pecado y la vergüenza de tocarse inculcados por su madre, quien 
creía que su hijo estaba poseído. Brando recuerda las burlas que sufría desde pequeño porque a los doce años no había tenido sexo, según sus amigos, debido a la maldición de haber sido bautizado con un "nombre de mayate". Sin embargo, en esta lucha por cumplir un proyecto autónomo de existencia y de sobrellevar las burlas y las acusaciones de su madre, Brando recurre en repetidas ocasiones al intento de reconocerse en el espejo: "miraba largamente su reflejo sin encontrar la menor presencia de lo satánico, lo demoníaco, solo su cara ojerosa y mofletuda, la mirada torva de siempre, la imagen banal de lo cotidiano" (166). En sus ataques de rabia se volvía a mirar al espejo para encontrarlo terriblemente oscuro:

una oscuridad en la que ni siquiera existía el consuelo del resplandor de las llamas incandescentes del infierno; una oscuridad desolada y muerta, un vacío del que nada ni nadie podría rescatarlo nunca: ni las bocas ávidas de los maricones que lo abordaban en los antros de la carretera, ni las escapadas nocturnas en pos de las orgías de los perros, ni siquiera el recuerdo de lo que él y Luismi habían hecho, ni siquiera eso. (193)

Tras asesinar a La Bruja, regresar a su casa y huir de ella después de encontrarse con el diablo transmutado en gato negro, Brando insiste en mirarse al espejo: "no había dos aros de luz demoníaca sino sus mismos ojos de siempre, hundidos y enrojecidos, ojerosos y desesperados, pero totalmente normales" (207). La mirada, por lo tanto, se vuelve el vehículo para reconocerse/desconocerse. Pero también su relación con Luismi es una relación de espejo: ambos jóvenes eran amigos y ambos decidieron asesinar a La Bruja. Finalmente, Brando sabe que no existe algo demoníaco en él, sino solo un vacío que todo lo abarca y una frustración por reprimir sus impulsos sexuales, los cuales lo arrojan a las fronteras de lo aceptable y de lo abyecto. Esto puede constatarse en la última escena en la que Brando aún está en libertad. Él se encuentra con un niño de labios rosados quien jugaba "maquinitas" y al que Brando pensaba convencer de llevárselo a las vías, someterlo y comprobar si sus pezones rosados derramaban jarabe de frambuesa y no sangre si se 
atrevía a mordérselos. Mas su deseo pederasta no logra cumplirse ya que, en ese momento, Brando es detenido por la policía.

\section{Los efectos estéticos de lo neofantástico}

A diferencia de los autores mexicanos nacidos en la década de los sesenta y los setenta quienes, en buena medida, intentaron deslindarse de la herencia de lo real maravilloso, el realismo mágico y la sombra del Boom, Melchor recupera lo que Jaime Alazraki - estudioso de los relatos de Kafka, Borges y Cortázar- denomina "neofantástico":

lo neofantástico asume el mundo real como una máscara, como un tapujo que oculta una segunda realidad que es el verdadero destinatario de la narración neofantástica. La primera se propone abrir una «fisura» o «rajadura» en una superficie sólida e inmutable; para la segunda, en cambio, la realidad es ... una esponja, un queso gruyere, una superficie llena de agujeros como un colador y desde cuyos orificios se podría atisbar, como en un fogonazo, esa otra realidad. (29)

Alazraki distingue la intención del relato neofantástico en contraposición a la intención del relato fantástico, que se decanta por provocar un miedo inexplicable al lector quien, por momentos, pone en duda la lógica de los acontecimientos. Esta postura no se adopta frente a lo neofantástico ya que en esta tendencia lo sobrenatural se introduce naturalmente en la narración sin que esto provoque extrañeza o duda. Lo insólito resulta una metáfora de una segunda realidad que, aunque parezca fantástica, deriva de la realidad efectiva que habitan los personajes y lo sobrenatural es, simplemente, expresión de la cotidianidad. En el plano de la segunda realidad —la insólita - se alcanza a vislumbrar la primera realidad: la ordinaria, y ambas realidades se suman para crear una tercera realidad en la que los personajes no cuestionan a ninguna de las dos: la ambigua, ambivalente, fronteriza e híbrida. 
Por su parte, F. Javier Ordiz, menciona que en la literatura mexicana de la segunda mitad del siglo XX hay una presencia constante de lo insólito que implica mucho más al lector y que lo vuelve partícipe y cómplice de lo que él llama "efecto fantástico", que "depende sobre todo del choque, el contraste o la tensión entre una realidad constatable, objetiva e incluso cientifica, y el universo de 10 insólito, de lo no posible" (124). Esta oposición entre lo posible y lo imposible es una constante en las dos novelas de Melchor quien, desde las primeras páginas, acude a referentes del imaginario y el folclor mágico-fantástico que sirven para justificar acciones de los personajes y para explicar las consecuencias de sus actos abyectos y moralmente condenables. Otra constante en lo neofantástico es el empleo de ambientaciones, atmósferas y elementos naturales que abonan al efecto fantástico y a la aceptación de lo sobrenatural como otra cara de la realidad.

En Temporada de huracanes vemos este regreso a los seres del imaginario fantástico, específicamente a la figura de la bruja, quien no solo es imaginario sino personaje foco en la novela y cuya identidad se revela en una vuelta de tuerca inesperada. Los rumores sobre sus poderes, los mitos alrededor de su origen diabólico y los temores que acechan a la población arropan un temor mayor que se va revelando conforme avanza la historia y se va descubriendo el horror bajo la sentencia "el hombre es un lobo para el hombre". Aquí lo sobrenatural no rompe con la lógica y con el orden de la rutina. Se percibe como un lenguaje a descifrar para comprender que una amenaza puede leerse semióticamente en índices de la naturaleza ya sea como animales, ya sea como fenómenos meteorológicos. Las creencias ominosas aparecen cuando los personajes se encuentran en medio de un estado de angustia, de paranoia, de terror. Así, encontramos que Norma recuerda a "... un chaneque de rostro arrugado y ralos cabellos que les lanzaría un conjuro para enloquecerlas, o para hacerlas caminar en círculos por aquella vereda oscura por toda la eternidad, entre el desquiciante zumbar de las chicharras y los alaridos que periódicamente lanzaban los tapacaminos de ojos colorados" (Melchor 149); o bien, ante la aparición de un gato negro en casa de La Bruja: 
Brando supo entonces que aquel animal rabioso, aquella bestia que bufaba en la oscuridad era el diablo, el diablo encarnado, el diablo que lo venía siguiendo desde hacía tantos años, el diablo que por fin venía para llevárselo al infierno, y supo también que si no corría, que si no escapaba en aquel instante de la casa se quedaría atrapado con la horrible bestia en aquella oscuridad para siempre... (206)

La novela es rica en historias del imaginario fantástico que, de tanto repetirlas, se vuelven parte de la identidad de una colectividad: "Dicen que en realidad nunca murió, porque las brujas nunca mueren tan fácil. Dicen que en el último momento, antes de que los muchachos aquellos la apuñalaran, ella alcanzó a lanzar un conjuro para convertirse en otra cosa..." (215). Es evidente una naturalización del hecho sobrenatural a través del uso del rumor como estrategia narrativa. En una comunidad de hablantes se forjan las verdades a través de la aceptación de estas, de su verbalización y de su enunciación como sentencias incontestables. Las mujeres de La Matosa salen por las tardes a compartir e intercambiar las historias sobrenaturales que les otorgan identidad colectiva y que forman parte del imaginario de leyendas e historias con las que se reafirma un sentimiento de pertenencia. Así, el momento del día para recuperar lo insólito e inexplicable es el atardecer:

la hora en que las mujeres se sientan a contar historias mientras vigilan con más atención el cielo, en busca de aquel extraño animal blanco que se posa sobre los árboles más altos y lo contempla todo con cara de querer advertirles algo. Que no entren a la casa de la Bruja seguramente...Que les cuenten cómo algunos han salido espantados de ahí, mareados por la peste que todavía se respira adentro, aterrorizados por la visión de una sombra que se despega de las paredes y que comienza a perseguirlos. Que respeten el silencio muerto de aquella casa, el dolor de las desgraciadas que ahí vivieron. Eso es lo que dicen las mujeres del pueblo: que no hay tesoro ahí dentro, que no hay oro ni plata ni diamantes ni nada más que un dolor punzante que se niega a disolverse. (218) 
En el ejemplo anterior, no solo encontramos la recurrencia a lo sobrenatural, sino que este elemento es el que deriva en el aspecto emotivo del texto: más allá de la aceptación de las sombras, la transmutación de los espíritus en animales fantasmáticos, las mujeres de La Matosa aseguran que lo único que queda en la casa de las tragedias es un dolor que no se olvida. Dolor que puede ser recordado gracias a las mismas historias legendarias sobre La Bruja y su aciago fin. Así, pues, el acto de narrar desde lo insólito y sobrenatural sirve como refuerzo del acto empático de solidarizarse con la desgracia ajena.

La aceptación de lo insólito como parte de la vida corriente de los habitantes de La Matosa ayuda a dar una explicación a los sucesos de su vida cotidiana. Hay una constante necesidad de adjudicarle a los eventos desgraciados un poder sobrenatural que no solo afecta a los directamente involucrados, sino que tiene una resonancia colectiva:

Esa fue también la época en que la gente empezó a ver al animal volador que por las noches perseguía a los hombres que regresaban a casa por los caminos de tierra entre los pueblos, las garras abiertas para herirlos, o tal vez para llevárselos volando hasta el infierno, los ojos del animal iluminados por un fuego espantoso. (17)

Y en este mundo en el que lo insólito y lo habitual conviven, los elementos de la naturaleza son mencionados como signos y señales del devenir de los mortales:

Porque de repente el cielo se puso negro, se llenó de nubes que un viento súbito arrimó contra los cerros, azotando las matas del cañaveral contra el suelo... y [Munra] vio clarito cómo de las nubes oscuras surgía de pronto un rayo mudo que caía sobre un árbol que se achicharró en absoluto silencio, un silencio tan espeso que por un momento hasta pensó que se había quedado sordo porque lo único que alcanzaba a oír era una especie de zumbido seco que rebotaba dentro de su cabeza. (61) 
Se trata de señales que anuncian la desgracia por venir y que sirven como imágenes del pathos de los personajes. Como se ha señalado anteriormente, las relaciones de los humanos en estas novelas están cargadas de vacío y rupturas. Si a esto se agrega la carga sobrenatural y la resignificación de los fenómenos naturales, entonces se verá que el actuar de los mortales está inexorablemente imbricado con los designios de fuerzas ajenas a su voluntad. A pesar de ser ellos quienes cometen los actos moralmente censurables, hay una tendencia a relacionar su actuar con la canícula, las aves, los rayos y las tormentas. La Matosa es una sociedad animista en la que no hay necesidad de buscar explicaciones racionales a los signos indiciarios que la naturaleza presenta y de los que tampoco es posible escapar.

El clima cobra relevancia en Temporada de huracanes puesto que la canícula se torna violenta y aplastante; se proyecta una naturaleza tan agreste como la naturaleza humana: amenazante, despiadada e indiferente, pero siempre acechando y mandando sus señales a los que sean capaces de entenderlas. Hay una relación indisoluble entre la violencia del clima y la violencia en el reino de los mortales, como si esta última estuviera en función de designios ajenos a la voluntad y a la decisión humana:

Dicen que el calor está volviendo loca a la gente, que cómo es posible que a estas alturas de mayo no haya llovido una sola gota. Que la temporada de huracanes se viene fuerte. Que las malas vibras son las culpables de tanta desgracia: decapitados, descuartizados, encobijados, embolsados que aparecen en los recodos de los caminos o en fosas cavadas con prisa en los terrenos que rodean las comunidades. Muertos por balaceras y choques de auto y venganzas entre clanes de rancheros; violaciones, suicidios, crímenes pasionales como dicen los periodistas. (217)

En una especie de sincretismo ideológico, los habitantes de La Matosa creen en la brujería, los amarres, los trabajos de magia negra, los hechizos que dejan enrarecido el aire; pero también creen en Dios, en Jehová y en san Judas. Así, se cuenta que las misas que oficiaba el padre Casto estaban dedicadas a: 
los endemoniados de la parroquia, a todas esas gentes que por andar creyendo en la brujería quedaban en poder de las fuerzas oscuras, de las legiones de demonios y espantos sueltos por el mundo, espíritus malignos que nomás andaban a las vivas viendo quién les daba entrada con pensamientos impíos, con rituales de hechicería y creencias supersticiosas que por desgracia abundaban en aquella tierra debido a las raíces africanas de sus habitantes, a las costumbres idólatras de los indios, a la pobreza, la miseria y la ignorancia. (160)

Es interesante observar que, en el ejemplo anterior, se hace referencia a un cúmulo de razones histórico-sociales por las cuales los habitantes creen en las fuerzas sobrenaturales y que, en cierta forma, justifica la aceptación de una realidad que traspasa la frontera de lo racional y lo científicamente comprobable. Todo esto contribuye al carácter neofantástico de la novela, a través del cual se desenmascara la segunda realidad a la que alude Alazraki: la realidad en la que la metáfora desvela una significación social que trasciende el mero guiño fantástico y que vuelve porosas — si no es que inexistentes- a las fronteras entre el pensamiento cientificista-racionalista, el pensamiento mágico-animista y el pensamiento cristiano-pagano.

En Falsa liebre el efecto neofantástico se da a partir de la preponderancia por relacionar lo sobrenatural con los elementos de la naturaleza. Un leitmotiv es la aparición constante de los zanates quienes son mencionados en once ocasiones ${ }^{3}$ a lo largo de la novela y cuya significación general se concentra en su papel como testigos mudos del drama humano: "Una sombra negra se asomó por la ventana. Los dos chicos respingaron. Un zanate macho — un ejemplar soberbio, pensó Vinicio, pasado el susto- se había posado en el alféizar y los escrutaba, con la cabeza vuelta de lado" (85). La negrura de esta ave se relaciona también con la negrura del mar, del bosque, de la carretera y de la playa. Hay una oscuridad constante y una in-

${ }^{3}$ En la edición de Almadía (2013) estas referencias aparecen en las páginas 26, $66,81,85,91,102,118,152,156,167$ y 188. 
clinación por los ambientes sombríos de la penumbra: "Desde ahí arriba, la ciudad era una maraña de luces que los goterones sobre el vidrio y los ojos de Andrik refractaban en nebulosas coloridas. El mar cercano, en cambio, se confundía con la noche: pura negrura sin horizonte" (16). Y, unas páginas después:

El alumbrado era escaso; los arbotantes que sobrevivían a la temporada de tormentas emitían una luz mortecina que los pinos tristes — torcidos hacia el camino, deformados por el viento- ahogaban con sus ramas plumosas, cargadas de agujas secas. . . . Las olas reventaban con escándalo a diez metros de la ventanilla del chico. El mar bullía, negro verdoso, coronado de espuma amarillenta. El cielo era oscuro también, pero su negrura tenía un tinte plomizo. Ya no llovía: los cúmulos de tormenta se alejaban de la costa. Cargados de relámpagos, fosforecían en su apresurado camino hacia las montañas. (18-19)

Los ambientes descritos ahondan en la pesadumbre de los propios personajes. De manera similar, al interior de ellos se agita un mar oscuro de contradicciones, desesperación, odios y deseos de venganza y huida. La construcción de las atmósferas a partir de prosopopeyas y símiles contribuye a la caracterización de escenarios sensoriales teniendo como mayor soporte la descripción de estímulos visuales, auditivos y olfativos y, a la vez, se percibe el animismo atribuido a los elementos naturales como fuerzas influyentes en las emociones de los personajes:

No podía distinguir el mar del cielo: ambos eran completamente negros, como si la playa fuera una plataforma que flotara en medio de la nada. El sonido de las olas le pareció el efecto del vacío, como el rumor que se escucha al ponerse un caracol muerto en la oreja... . Era como si estuviera sentado en la orilla de un abismo, como si aquella nada siniestra y caníbal de la que le hablaban en ese libro que había leído de pequeño, La historia interminable, hubiera ya devorado hasta la 
última mota de polvo del universo y no quedara nadie más en el mundo -nadie más que él- para contemplarla. Sintió vértigo y miró hacia arriba. La luna le sonrió desde las alturas, convertida en un cuerno de plata. Las estrellas lo miraban, indiferentes. (181)

De la misma forma como sucede en Temporada de huracanes, en Falsa liebre la presencia de la naturaleza refuerza su carácter dominante $\mathrm{y}$, al mismo tiempo, inconmovible ante el desasosiego y desamparo de los personajes. En un sentido neofantástico, la segunda realidad de la que habla Alazraki, y que se refiere a la metaforización de lo sobrenatural, aquí es presentada como una línea narrativa en paralelo. Es decir, por un lado, hay una línea sobre los personajes y sus peripecias y, por el otro, hay una línea sobre la naturaleza y su papel contemplativo que parece más el de un espectador indiferente que el de un espectador involucrado con lo que observa. Además de esta preponderancia por la afectación emocional arraigada en la influencia de la naturaleza, la novela también introduce algunas creencias sobrenaturales; especialmente en Susana, la madre de Vinicio, quien vive obsesionada con la visita fantasmagórica de su marido muerto y con aquellas creencias con las que educó a su hijo:

chaneques que entraban en la casa para robarse a los niños y sustituirlos por pequeños monstruos que la madre amamantaba entre terribles dolores; muchachas perdidas que entablan comercio carnal con el demonio, con Satanás en persona, un catrín de capa y moño que escondía sus patas de cabra bajo pantalones de seda; borrachos que, al regresar a casa en la madrugada, se topaban con la Niña de Blanco o con los nahuales: gorriones gigantes que hablaban, marranas que caminaban en dos patas y echaban lumbre por los ojos, pavas que trepaban los techos y lanzaban una tripa a través de la cual succionaban la sangre de los durmientes. (107)

Al igual que en Temporada de huracanes, aquí se recuperan las supersticiones propias del folclor y las creencias populares que, si bien, 
tienen un menor efecto en los personajes de esta novela, sí cumplen con su función neofantástica al robustecer el entorno con una realidad en la que lo insólito y lo incomprobable tienen cabida en las ideologías de los personajes. Por último, en Falsa liebre, hay una mayor tendencia a hibridar lo sobrenatural con lo natural. Por ello, el efecto ambivalente y ambiguo conlleva un traspasar la frontera de aquello que, de entrada, parece no tener una explicación, pero que termina siendo aclarado por los detalles naturalistas de la escena:

El suelo ahí abajo era mullido e inestable. Las ramas bajas de los pinos le azotaban el rostro y le pinchaban las manos extendidas. Había cosas ahí, en la oscuridad; presencias aleteantes que se posaban sobre sus mejillas y le acariciaban el cráneo sudoroso con pequeñas patas fantasmales. Se llevó las manos a la cabeza y tocó una de ellas: era grande como un murciélago, pero frágil y mucho más liviana. Se la arrancó a gritos; las alas de la mariposa se deshicieron como papel viejo entre sus dedos. Otra más se posó sobre su boca, atraída por el olor de su saliva. Zahir, frenético, se golpeó el rostro a manotazos. Rodó por el suelo para sacárselas de encima. El polvillo que desprendían sus cuerpos le quemaba los ojos y le impedía abrirlos. (196)

\section{La estética de lo abyecto}

A diferencia de las escritoras que preceden su generación, entre los temas de Melchor no se encuentran la reivindicación de las libertades del cuerpo femenino, la exploración sexual como derecho inalienable ni tampoco el empoderamiento resignificado de las mujeres como ciudadanas autónomas. Lo que sí se halla en su narrativa es una fuerza argumental y una potencia estilística que dan como resultado obras cargadas de una emotividad ambivalente, en la que categorías opuestas y situaciones desestabilizadoras confluyen, y en las que no hay una inclinación por ningún género en particular, sino que todas las construcciones de género son identidades humanas 
contradictorias y abyectas. El 14 de mayo de 2020, en una charla organizada por el Tecnológico de Monterrey, Fernanda Melchor alude a una entrevista de 2012 en la que se le preguntó si se consideraba feminista y recuerda que:

un montón de morras, como por ejemplo yo o Tania Tagle, dijimos que no porque en ese entonces . . . era un vocablo que te hacía dudar, ¿no? como que las personas que conocíamos que eran feministas nos parecían ... como sospechosas, ¿no? como histéricas; era algo que no me latía. . . . la cosa era que no necesariamente a mí me gustaba asumirme como feminista. Era algo que no había reflexionado lo suficiente y, sin embargo, yo creo que del 2012 para acá fue un asunto que inevitablemente tuve que empezar a tratar . . . Pero fue algo que empezó a colarse en mi trabajo.

Más adelante, en esta charla, hace un recuento sobre su primera novela Falsa liebre, cuya trama se centra en las peripecias de cuatro varones. $\mathrm{Al}$ respecto, la autora comenta:

Yo me dije: "oye tal vez también es feminista poder escribir de lo que se me dé la gana sin tener que escribir sobre mujeres" ... Y posteriormente, con Temporada de huracanes, ... . sí sentía que tenía yo esta deuda con personajes femeninos profundos que no fueran nada más personajes secundarios; que no fueran nada más la mamá de o la novia de, sino que fueran realmente personajes femeninos que, incluso, fueran centrales en la trama y en Temporada eso fue lo que intenté hacer. . . . Si analizan Temporada de huracanes, en realidad, todo se lleva a cabo por las decisiones que Norma toma: ese es el centro de la novela en realidad.

Más allá de colocar a un personaje femenino como detonante de la acción en su segunda novela, la autora hace en sus dos textos un ejercicio de deconstrucción de las categorías de género.

Consciente o inconscientemente, Melchor crea personajes y situaciones que trascienden la polarización binaria en la construcción 
del género y ofrece un catálogo de identidades sexuales abyectas que incluyen los binomios hombre/mujer y el conjunto heterosexual/ bisexual/homosexual. Para sustentar estas ideas, es preciso retomar lo que Judith Butler menciona respecto a los cuerpos abyectos en Cuerpos que importan:

Hay un vínculo entre la homosexualidad y la abyección, ... hay una posible identificación con una homosexualidad abyecta en el corazón mismo de la identificación heterosexual. Esta economía de repudio sugiere que la heterosexualidad y la homosexualidad son fenómenos mutuamente excluyentes, que sólo se pueden hacer coincidir permitiendo que sean uno culturalmente viable y el otro un asunto pasajero e imaginario. La abyección de la homosexualidad sólo puede darse mediante una identificación ... de la que hay que renegar; una identificación que uno teme hacer sólo porque ya la ha hecho, una identificación que instituye esa abyección y la sostiene. (169)

El repudio a saberse homosexual o a identificarse con algún rasgo que pueda relacionar al sujeto heterosexual con la performatividad abyecta de la homosexualidad son rasgos de esta resignificación del sexo/género que Butler presenta en su obra. Para ejemplificar lo anterior, se presentará un análisis ${ }^{4}$ sucinto de Brando, personaje fundamental en Temporada de huracanes y quien mejor ilustra la abyección homosexual:

porque una cosa era dejarse querer por los putos, dejarse invitar unos tragos y una chela y ganarse un quinientón por

\footnotetext{
${ }^{4}$ En este apartado referente al concepto abyección en la teoría de Judith Butler —en relación con el binomio heterosexualidad/homosexualidad — nos centraremos únicamente en Temporada de huracanes, ya que la abyección en Falsa liebre está presente, pero se relaciona más con la materialidad de los fluidos corporales; la presencia de la violencia a través de la representación de la muerte, temas que se abordarán más adelante en este apartado.
} 
soportar sus puterías, o incluso por cogérselos un rato por el culo o por la boca, y otra cosa era ser un puerco asqueroso como el pinche Luismi cuando se besuqueaba y se fajaba con la Bruja. Quién sabe por qué le daba tanta tirria a Brando ver eso; ... tal vez porque en el fondo todo eso de besarse con los gansos le parecía algo asqueroso, un atentado innoble a su hombría, y cómo era posible que el Luismi se atreviera a besar a la loca esa frente a todos, si Brando siempre había pensado que Luismi era un bato bien derecho, bien machín y bien chido (181)

Brando es un hombre que se ubica en la frontera de su deseo y la aberración provocada por este. En él se proyecta lo que Butler apunta sobre la identificación discursiva que el imperativo heterosexual impone al individuo a través de la práctica de la heteronorma y el repudio a lo que se le oponga. En el ejemplo anterior, el narrador intradiegético presenta con claridad cómo, a los ojos de Brando, Luismi era un hombre "machín", heterosexual y además "bien derecho", un hombre íntegro. Aquí se asocia la heterosexualidad con la convicción impuesta de que un hombre "de verdad" también es un hombre moralmente confiable, alguien recto que no caería en el deseo abyecto de lo chueco, lo torcido, lo volteado y lo desviado.

Butler señala que, además de los discursos impuestos por la identidad heteronormada, el sujeto que rechaza lo abyecto debe crear a esos otros a los que hay que rechazar y de los que hay que huir. Se les da visibilidad, aunque se les niegue su condición de sujetos. Explica Butler que:

lo abyecto designa aquí precisamente aquellas zonas "invivibles", "inhabitables" de la vida social que, sin embargo, están densamente pobladas por quienes no gozan de la jerarquía de los sujetos; pero cuya condición de vivir bajo el signo de lo "invivible" es necesaria para circunscribir la esfera de los sujetos. (20)

Para Brando, la máxima aberración es convertirse y vivir como aquello que él mismo detesta y, al mismo tiempo, desea: la mascu- 
linidad ambivalente de Luismi, camarada y cómplice del asesinato que cometen. Brando habita un espacio emocional paradójico de deseo/repulsión hacia su amigo y este descontrol comienza a vislumbrarse en los celos que siente, primero hacia el ingeniero que enamoraba a Luismi y, posteriormente, hacia Norma:

y se jaló la verga con la palma mojada de baba, entre gruñidos culpables mientras se imaginaba cómo sería ensartarse a Luismi por detrás al mismo tiempo que lo chaqueteaba suavecito para que él también pudiera venirse junto con Brando, venirse en cuatro patas como el perro que era, como la perra flaca y mugrosa que era, una perra caliente que meneaba la cola con lujuria cada vez que veía llegar a su ingeniero, su puto ingeniero. (187)

La desazón que en Brando provoca la relación con Luismi adquiere matices abyectos y criminales que van aumentando conforme se acercan dos impulsos incontrolables: el deseo por poseer a su amigo y el deseo de matarlo en venganza por ser la encarnación de lo que más anhelaba:

en vez de haber huido como un puto cobarde lo que tendría que haber hecho era montarse sobre Luismi y aprovechar la indefensión de su sueño para estrangularlo con las manos, o mejor aún, con el cinto de sus pantalones ... por miedo a reunirse con sus amigos y que estos, enterados con lujo de detalle de lo que había pasado entre él y Luismi, lo castraran frente al pueblo entero llamándolo choto, puto, maricón, carajo. (189)

A lo largo del episodio enfocado en Brando observamos cómo el binomio deseo/odio va fermentándose en él hasta estallar en el acto más violento contra otro ser humano: el asesinato. Sin embargo, la víctima de Brando no es ese otro deseado, sino el otro más repudiado, el que se ubica en las antípodas de su identidad heteronormada y que, por consiguiente, se presenta como el cuerpo más abyecto en Temporada de huracanes : la Bruja. En este personaje se 
sintetizan las categorías de la abyección social que menciona Judith Butler: lo no simbolizable, lo indecible y lo ilegible. La Bruja es un hombre que, desde pequeño, adquiere una identidad ilegible, una identidad impostada por su madre, La Bruja Mayor, y por el rumor y la mitificación del pueblo. A La Bruja se le percibe como ese ser sobrenatural del cual no se debe hablar — es indecible — para evitar ser víctima de un maleficio o del mal de ojo; pero es quien, al mismo tiempo, se convierte en oráculo y protección de mujeres desesperadas, prostitutas de la carretera y varones bisexuales quienes, a pesar de buscarla para obtener un beneficio económico, llegaron a convertirse en su círculo social. Se trata de los marginados, los que no pueden ser nombrados a la luz, pero de quienes se sabe todo en La Matosa. En la configuración de La Bruja se concentra la ambivalencia de quienes sienten por ella una fascinación y un rechazo al mismo tiempo. Es el sujeto-no-sujeto, el humano que traspasa su limitado poder para hacer el mal y hacer el bien; es la vestida eufórica que canta baladas y baila desenfrenada en orgiásticas ceremonias con los mayates del pueblo: los jóvenes activos que la adoptan como el símbolo innombrable e inhabitable de su propia abyección.

La Bruja es el personaje con cuyo cadáver inicia la acción en la novela. Para Kristeva, el cadáver representa la máxima abyección de un cuerpo otrora animado y en el que se proyecta el rechazo natural hacia la muerte:

los cinco rodeados de moscas verdes, reconocieron al fin lo que asomaba sobre la espuma amarilla del agua: el rostro podrido de un muerto entre los juncos y las bolsas de plástico que el viento empujaba desde la carretera, la máscara prieta que bullía en una miríada de culebras negras, y sonreía. (12)

Finalmente, en esta última representación de lo abyecto, se halla un binomio adicional que es propio del contexto mexicano. No solo se rechaza al homosexual, sino que, en México, se rechaza al pobre y a aquel cuyo color de piel es más moreno.

De acuerdo con la investigadora del Programa Universitario de Estudios de Género de la UNAM, Susana Vargas Cervantes: 
Las diferencias económicas materializadas en una sociedad socialmente estratificada a través de la clase y las tonalidades de la piel apuntan a un proceso de subjetivación en el que la relación de continuidad y coherencia entre el género, el sexo, el deseo, la orientación y la práctica sexual está profundamente intersectada por la clase y las tonalidades de piel. (171)

Vargas Cervantes enfatiza que en México no es lo mismo ser gay que ser maricón, puesto que la primera denominación alude a un hombre blanco homosexual cuya posición económica le ubica en un sector privilegiado y cuyo comportamiento reproduce la heteronorma; mientras que el maricón, el joto, el puto y la vestida son categorías a las que pertenece aquel mexicano homosexual, pobre, moreno y afeminado, que lo ubican de inmediato en la abyección sexual y social. Así, en Temporada de huracanes vemos una clara correlación en Brando entre el deseo de poseer a Luismi y, al mismo tiempo, el deseo materialista de tener una mejor condición económica; su obsesión por objetos de consumo — sus tenis Adidas blancos con rojo- es tan grande como su obsesión por el cuerpo deseado de Luismi, a quien no perdonaría haberlo visto "con aquella escuincla que según Luismi era su esposa, una mocosa con cara de india" (197).

La descripción física de los personajes es una constante en las dos novelas de Fernanda Melchor. Se habla de los cuerpos y los contrastes entre los broncíneos torsos de efebos y los rancios cuerpos de los más viejos. Se presentan los cuerpos humillados, objeto del escarnio como el de Yesenia en Temporada de huracanes:

Yesenia se hartaba de gritarle [a Luismi] y perdía el control y agarraba a su primo de los pelos y le tundía el cuerpo flacucho a puñetazos . . con ganas de que se muriera . . . y dejara de una vez de fastidiarla, de lastimarla, de llamarla siempre con ese apodo que la abuela le puso de chica y que Yesenia odiaba con toda su alma y que se le había pegado de tal forma que todo el pueblo la conocía ya como la Lagarta, por fea, prieta y flaca recitaba la abuela, igualita a un teterete parado sobre dos 
patas. Lagarta, lagarta, canturreaba el chamaco baboso, tiene pelos en la cucaracha, ahí mero . . . frente a la gente chismosa que lo escuchaba todo y que se reía (43)

En Poderes de la perversión, Julia Kristeva define lo abyecto como: "eso que perturba la identidad, el sistema, el orden. Aquello que no respeta las fronteras, las posiciones, los roles, que se emparienta con la transgresión y con la perversión” (27). Por su parte, Inés Ferrero Cándenas desarrolla la idea de lo abyecto en un estudio sobre el cuento "Orfandad" de la escritora mexicana Inés Arredondo. Dice Ferrero Cándenas:

En términos muy generales podría decirse que lo abyecto es un desafío o ataque, tanto para el sujeto individual como para la sociedad en la que habita. Es "aquello" que debemos expulsar de nosotros mismos o de nuestro entorno para que nuestros límites (corporales, sociales, psíquicos) no se vean transgredidos o desestabilizados. Puede comprender desde los deshechos corporales (excremento, comida, secreciones) hasta todos aquellos seres que la sociedad margina o excluye. Por otro lado, lo abyecto también se vincula de forma decisiva con la configuración de los lindes de la subjetividad e identidad. (149-50)

Una constante en las novelas de Melchor es la marginación de los personajes. Se trata de marginaciones sociales, pero también sexuales, emocionales, relacionales, afectivas, intelectuales, físicas, corporales, sensoriales y psíquicas. Sus personajes circulan por la periferia de los valores moralmente establecidos dentro de las normas de convivencia; traspasan la concepción de lo correcto y, algunos de ellos, se regodean en el crimen: homicidio, secuestro y robo. Asimismo, los personajes y las situaciones en las que se encuentran obligan a que el lector cuestione sus propios límites imaginativos al concretar el sentido de la narración. Esto conlleva una desestabilización e incomodidad derivadas de la concreción explícita de lo abyecto en las escenas de las dos novelas. Como complemento a 
estas ideas, Silvana Mandolessi y Emmy Poppe mencionan que lo abyecto también abarca:

La emoción del asco, experimentada ante objetos considerados impuros tales como las excreciones del cuerpo, sangre, pus, sudor, excrementos, vómitos, flujo, menstrual o el cadáver [por lo que] resulta esencial, para catalogar una estética como abyecta, que el asco juegue un papel central, evocado en la presencia de figuras u objetos repugnantes, monstruosos, desagradables, ya sea por sus características sensoriales o por sus cualidades morales. (18)

Precisamente, en cuanto a las cualidades morales, Kristeva también señala que la categoría de lo abyecto abarca a los sujetos criminales que tienen la conciencia limpia, a los violadores cínicos cuya desfachatez cuestiona la frontera entre el bien y el mal, o bien, a los traidores y a los mentirosos, ya que lo abyecto recuerda la fragilidad del orden social encarnado en la supuesta fuerza de la ley y de la conducta asociada con la normalidad.

Respecto al asco, Arleen F.S. Salles menciona que:

Sea provocado por nociones abstractas acerca de la violación de derechos, sea producto de desencadenantes carnales específicos, el asco parece funcionar como un medio importante para internalizar prohibiciones morales. La mayoría de las sociedades humanas repudian algunos tipos de comportamiento que consideran potencialmente contaminantes. (30)

Así, el asco opera también como un mecanismo de defensa moral con el que se condenan actos que se desvían de lo moralmente aceptable y lo tradicionalmente convenido por las sociedades dentro de las normas de convivencia. En resumen, el asco se presenta frente a los actos socialmente abyectos. La violación, la zoofilia, la pedofilia, las orgías, el abuso de sustancias tóxicas, el exhibicionismo y el lenguaje cargado de connotaciones sexuales violentas son algunos ejemplos constitutivos de la diégesis de ambas novelas. Por consiguiente, pueden generar en los lectores el asco antes mencio- 
nado y condicionarle a tomar una respuesta ante el impacto que los textos provocan en ellos. Sea una respuesta favorable o desfavorable, en ambos casos los lectores son compelidos a reaccionar a las dos novelas, ya que las huellas que dejan tanto la abyección como el asco son marcas que remiten a los aspectos tabú más reprimidos en nuestras sociedades.

Así, encontramos en la narrativa de Melchor abundantes ejemplos de lo abyecto tanto en un sentido corporalizado como en un sentido moral. A continuación, se presentan ejemplos que ilustran lo anterior. En Temporada de huracanes se describe el asesinato de La Bruja descarnada y crudamente:

Entiérraselo en el cuello, le dijo a Luismi ... pero el pendejo maricón de Luismi le hizo un tajo bien pedorro y no alcanzó a cortarle ninguna vena importante, nomás hizo que la Bruja abriera los ojos bien grandes y que les pelara los dientes llenos de sangre, y Brando ... guio la cuchilla hacia la garganta de la Bruja, una vez y luego otra, y una tercera vez más, por si las moscas, ora sí atravesando las capas de piel y de músculo, las paredes de las arterias y el cartílago de su laringe e incluso los huesos de las vértebras, que a la tercera cuchillada se partieron con un chasquido seco que hizo llorar al choto de Luismi como una criatura (204)

Como se ha mencionado anteriormente, Brando es uno de los personajes más fragmentados y en constante lucha contra su propia identidad abyecta. Aunado a su carácter contradictorio y encolerizado, hay en la narración de su sexualidad una marcada abyección que despierta en él una ambivalente y violenta respuesta:

lo que verdaderamente le hubiera gustado ver era cómo el perro se cogía a la vieja: cómo después de mamarle la verga, la vieja se daba la vuelta y el perro la montaba despiadadamente hasta llenarle el coño sonrosado de leche pegajosa, leche de perro caliente escurriendo por los muslos pálidos de la chica que gemía y se retorcía tratando de despegarse de aquel perro asqueroso. (165) 
Otros rasgos de esta respuesta abyecta al sexo los encontramos en su deseo zoofílico provocado por la imagen de los perros apareándose por las noches en los sitios oscuros, marginados; así como en su fascinación y, a la vez, espanto ante el sexo en grupo, o bien, en ser parte de la violación a una joven alcoholizada quien, inconsciente, lo orina cuando este la penetra, a lo que él reacciona golpeándola salvajemente: "Brando la hubiera seguido golpeando, hasta sumirle la cara y tumbarle los putos dientes y tal vez hasta matarla, por haberle ensuciado la verga ... pero sobre todo por haberlo dejado en ridículo frente a la banda" (173).

Melchor juega con una estética de lo abyecto en la que pone de relieve las concepciones morales maniqueístas basadas en la idea de polos opuestos: animalidad-humanidad, femenino-masculino, heterosexual-homosexual, vida-muerte e inocencia-perversión. Sobre este último binomio, en el episodio VI se ofrece un ejemplo tanto abyecto como carnavalesco al describir la escena de una niña convertida en reina del carnaval. Aquí se halla una clara distinción entre lo permitido y lo moralmente prohibido que, aunque censurado, se narra explícitamente:

la reina, una niña apenas, envuelta en tules y brocados como una princesa de otro siglo; una nena de mirada perdida y sonrisa impostada que sacudía sus gráciles miembros al ritmo sincopado que tronaba desde la pared de bocinas a su espalda: A ella le gusta la gasolina, con una mano en la cintura y otra sujetando su corona, dale más gasolina, y aquella mirada vacía, casi espantada, cómo le encanta la gasolina, por las obscenidades que los ebrios a sus pies le gritaban con algo más parecido al hambre que a la lujuria, dale más gasolina, dispuestos tal vez a devorarla, a clavar sus dientes en aquella carne suave, pegada al hueso casi (170)

Por su parte, en Falsa liebre hallamos la abyección estrechamente relacionada con los cuerpos, con sus olores, sus texturas y los estímulos sensoriales a los que son sometidos. Llama la atención que, en esta novela, sean los personajes masculinos quienes tienen una ma- 
yor conciencia de su cuerpo al mirarse en el espejo y cuidar su imagen o, bien, al poseer cuerpos obesos y enfermos que les impiden encajar en un grupo determinado. Hay un claro interés en enfatizar las condiciones abyectas en las que Andrik, el personaje más joven de la novela, se desenvuelve y se enfrenta a la crueldad, la violencia y la agresividad de una realidad marginal. Los contrastes entre Andrik y los hombres con los que tiene sexo son una constante. $\mathrm{Al}$ referirse a los hombres con los que se prostituye se dice que estos:

pagaban por llenarle la oreja de saliva, por verlo masturbarse; otros se pasaban horas con la cara enterrada en su culo. Uno incluso se había negado a que Andrik se desnudara: lo metió al cuarto de baño del motel y le pidió que aliviara su vientre y luego se marchara, sin jalar la cadena. Cerró los ojos. . . . El aire húmedo del sauna olía a sarro, al sudor del Puerco ventrudo que jadeaba en su oído y que intentaba besarlo. Le apestaba el aliento. El chico oprimió sus labios pero el hombre, empeñado en alcanzar el interior de su boca, machucó su barbilla con los dedos para abrirla y meter una lengua esponjosa, olorosa a masilla y pasta de clavo. Bésame, susurraba, bésame rico. (30)

En otro cariz igualmente abyecto, Zahir se halla en los límites de una personalidad desdoblada que, por un lado, se muestra tierno y protector hacia su supuesto hermano y, por el otro, es física y emocionalmente violento y dañino. Zahir se caracteriza por haber sido un niño abusado y violentado por su tía Idalia. En su existencia solo conoce humillaciones y comentarios mordaces sobre su obesidad y aparente idiotismo. Su abyección es razonable, aunque irracional tal y como se muestra en el momento en que el chico golpea a su anciana tía:

La vieja terminó en el suelo y Zahir la tundió a patadas. Cada golpe aflojaba algo pútrido en su interior, algo fétido y deforme como tejido cicatrizado, que revelaba el recuerdo de una tortura: las veces que lo dejó sin comer, las veces que tuvo que dormir en la calle porque no había llegado a la hora 
indicada; la vez en que le obligó a mamar de la teta de la perra de la vecina porque se atrevió a pedir leche en la merienda; la vez en que lo azotó con el cincho en los genitales por haber estado tocándoselos, o más pequeño, cuando al enjabonarlo durante el baño le frotaba con furia hasta excitarlo y luego le cruzaba el rostro a bofetones y lo llamaba enfermo. (201)

Como se ha dicho: la abyección irracional de los personajes tiene razones de ser. En este punto, es posible comenzar a delinear que la estética abyecta en la narrativa de Fernanda Melchor no es una estética de lo escandaloso y moralmente reprobable per se, sino que se trata de una estrategia necesaria para representar la complejidad humana desde el lado repulsivo, grotesco, amoral y fragmentado de nuestra condición. Sin embargo, ambas novelas dan un giro al abanico de abyecciones que van de lo pantagruélico a lo pornográfico, pues en ellas puede hallarse una potente crítica a la bestialidad humana que pone de manifiesto una constante exclusión del otro al que, de común acuerdo, se tacha de anormal, de indeseable y de repugnante.

Más allá de escandalizar por las descripciones gráficas y explícitas de lo abyecto, la narrativa de Melchor señala con aguda mirada los vicios de una sociedad podrida desde las entrañas, obsesionada con las distinciones de clase, el color de la piel, el origen étnico, la orientación sexual, las parafilias, los secretos, los rumores y las fracturadas identidades de género. Pero cabe advertir que no hay moralización ni prescripción ética en su narrativa, sino que, magistralmente, Melchor hace este señalamiento a partir de la estética de la abyección, el sarcasmo, la ironía, lo soez, la transcripción minuciosa de idiolectos populares, los albures, las canciones, los relatos orales, las creencias en lo sobrenatural y la brujería, así como la fuerte presencia de la naturaleza como una potencia emocional, patética y psicológica, tal y como se discutió en el apartado anterior.

Hacia el final de Temporada de huracanes la abyección se vuelve paradójicamente armónica gracias a que el último episodio es extremadamente conmovedor por ser extremadamente descarnado. En él se cuenta de un depósito fúnebre en el que el Abuelo recibe 
cadáveres humanos para luego enterrarlos. El sepulturero piensa que la oscuridad de la tumba aterrará a los muertos que llegan al depósito por lo que resuelve que:

Había que calmarlos primero, hacerles ver que no había razón alguna para tener miedo, que el sufrimiento de la vida ya había concluido y que la oscuridad no tardaría en disiparse . . . Ya viene el agua, les contó el Abuelo a los muertos, mientras contemplaba con alivio las nubes gordas que tupían el cielo. Bendito sea, ya viene el agua, repitió, pero ustedes no teman. Un goterón solitario cayó sobre la mano que empuñaba la pala. El Abuelo se acercó el dorso a la boca para lamer la dulzura de la primera lluvia de la temporada. . . . Ustedes tranquilos... ustedes no teman ni desesperen, quédense ahí tranquilitos. El cielo se encendió con la lumbre de un rayo, y un estruendo sordo sacudió la tierra. El agua no puede hacerles nada ya y lo oscuro no dura pa'siempre. ¿Ya vieron? ¿La luz que brilla a lo lejos? ¿La lucecita aquella que parece una estrella? Para allá tienen que irse, les explicó; para allá está la salida de este agujero. (222)

En esta misma línea analítica de lo que se ha llamado la armonización de lo abyecto, es posible leer en Falsa liebre un ejemplo que se nutre tanto de la extralimitación de las fronteras de lo permitido como de la sensibilidad y empatía hacia el sentimiento de orfandad humanamente descrito:

[Zahir] aprovechaba cada segundo de ausencia para arrinconar a Andrik, para suplicarle que se bajara las ropas. Nunca se negaba: era tan dulce que a veces tenía ganas de devorarlo. Su boca sabía a melaza, su cuerpo a mantequilla. Sus manos pequeñas lo tocaban con ternura, y eso nunca nadie jamás lo había hecho; nunca nadie había acariciado antes el cuerpo de Zahir, aquel cuerpo que a todo el mundo - incluso a sí mismo- le parecía monstruoso. Nadie nunca lo había despertado por las noches para buscar su calor, su lengua, sus besos. (200) 
Lo que se puede concluir de estas dos novelas es que, a pesar de hacer una punzante representación de lo abyecto, estas narraciones no se decantan por una moralización en torno a los atroces actos humanos. Tampoco romantizan al personaje marginal ni hacen de él un estereotipo, un héroe, un mártir o un esperpento. Son novelas crudas porque cruda es la existencia de sus personajes. Son emotivas porque emotiva es la contemplación de los lazos humanos fragmentados. En la escritura de Melchor se concluye que no hay maldad o bondad sin una razón de fondo; solo hay humanos atrapados en la realización certera de un destino infausto que proviene de un origen desgraciado marcado por el crimen, el abandono, la pobreza, la crueldad familiar, los deseos reprimidos y los sueños que nunca logran cristalizarse. A diferencia de escritoras de su generación tales como Valeria Luiselli (1983), Brenda Lozano (1981), Laia Jufresa (1983) o Verónica Gerber Bicecci (1981), Fernanda Melchor recupera lo neofantástico y lo real maravilloso como productos del sincretismo pagano de nuestras culturas y los convierte en una especie de "horrorismo mágico" en el que la única magia consistiría en encontrar un atisbo de compasión en el reino de los mortales. El carácter neofantástico en la narrativa de Melchor aporta a los textos una concepción más coherente de la relación que guarda el ser humano con la naturaleza y con lo que culturalmente se relaciona con la superstición y la presencia constante de lo insólito en el contexto mexicano. El uso del patetismo y de la prosopopeya, así como la creación de atmósferas naturales y de índices que presagian el estado emocional son recursos de lo neofantástico que enriquecen la ambigüedad de ambas novelas y que enmarcan la tragedia cotidiana de los personajes. A pesar de la hipervisibilización de la violencia y la abyección, en estas novelas no se deja de lado la posibilidad de una realidad alterna: la de las creencias fantásticas y la materialización de estas a través de la brujería, los duendes, los chaneques y las criaturas voladoras sin que nada de esto sea puesto en duda.

Melchor elige una estética de lo abyecto porque no hay otra forma de describir una realidad que es abyecta en sí. Esta estética de la abyección refuerza la idea tanto de Butler como de Kristeva, para quien la imagen del cadáver es el límite de la representación pues, 
ahí donde se ve un cuerpo desmembrado, el Yo es expulsado para convertirlo en mero objeto repugnante o, en el caso de la narrativa de Melchor, en objeto que recupera su cualidad humana a través de la poeticidad literaria que obliga a pensar en el otro como alteridad y no como despojo repulsivo. Recordemos que, desde el momento en que se emplea el concepto de lo abyecto para acercarse a las novelas, ya se está adoptando una postura sesgada que puede desviar la atención del texto como producto cultural y que puede reflejar una postura moralizante y no moralmente crítico-reflexiva. No hay que olvidar que, en cuanto se categoriza como abyectos a ciertos cuerpos y a ciertas acciones transgresoras, se está tomando una postura desde la normatividad que señala aquello que se sale de sus reglas.

Quizá por lo que debería apostarse, al acercarse a la literatura de Melchor, sea la aceptación de lo abyecto como una condición humana frecuente y necesaria, y no solo como un síntoma excepcional de una decadencia social o de una rebelión contra la heteronormatividad. Esto, en el último de los casos, bien podría ser la función moral de sus novelas - si es que existe una función moral de la literatura - , puesto que, al finalizar la lectura de estos mundos abyectos y siniestros, lo que queda reverberando en la conciencia del lector es la reflexión sobre la vulnerabilidad del bien y sobre ese otro Yo monstruoso, corrupto, marginal, oscuro, cargado de rencor; ser repudiado que, indudablemente, habita — activa o pasivamente- al interior de cada ser humano.

\section{Bibliografía}

Alazraki, Jaime. “¿Qué es lo neofantástico?”. Mester, no. 2, 1990, pp. 21-33.

Butler, Judith. Cuerpos que importan. Sobre los límites materiales y discursivos del "sexo". Paidós, 2012.

Ferrero Cándenas, Inés. "Cuerpo-abyecto-lenguaje: La experiencia del límite en 'Orfandad' de Inés Arredondo”. Hispanófila, vol. 169, 2013, pp. 147-157. 
Imbert, Gérard. Cine e imaginarios sociales. Cátedra, 2010.

Kristeva, Julia. Los poderes de la perversión. Ensayo sobre Louis-Ferdinand Céline. Siglo XXI, 2006.

Lucas, Julian. "Book Review: A Mexican Novel Conjures a Violent World Tinged With Beauty, "Hurricane Season" by Fernanda Melchor". The New York Times, 31 marzo 2020, www.nytimes. com/2020/03/31/books/review/hurricane-season-fernanda-melchor.html

Mandolessi, Silvana y Emmy Poppe. "Dos estéticas de lo sobrenatural: lo siniestro en El espinazo del diablo y lo abyecto en El laberinto del fauno de Guillermo del Toro". Revista Confuencia, vol. 27, no. 1, 2011, pp. 16-32.

Melchor, Fernanda. "Charla con Fernanda Melchor acerca de su obra literaria / Vox Orbis / Cátedra Alfonso Reyes". 14 mayo 2020, itesm.zoom.us/j/99090171841 - Falsa liebre. Almadía, 2013.

. Temporada de huracanes. Penguin Random House, 2017.

Ordiz Vázquez, F. Javier. "Incursiones en el reino de lo insólito. Lo fantástico, lo neofantástico y lo maravilloso en la narrativa mexicana contemporánea". Tendencias de la narrativa mexicana actual, editado por José Carlos González Boixo, Iberoamericana / Vervuert, 2009, pp. 123-140.

Salles, Arleen. "Sobre el asco en la moralidad". Diánoia, no. 64, 2010, pp. 27-45.

Vargas Cervantes, Susana. "Saliendo del clóset en México: ¿queer, gay o maricón?”. La memoria y el deseo. Estudios gay y queer en México, coordinado por Rodrigo Parrini Roses y Alejandro Brito, Universidad Nacional Autónoma de México / PUEG, 2014, pp. 151-175. 